This is a penultimate draft of a paper forthcoming in: British Journal of Aesthetics.

\title{
A linguistic specification of aesthetic judgments
}

\author{
Jochen Briesen \\ Institute of Philosophy, Freie Universität Berlin/ \\ Department of Philosophy, University of Konstanz \\ (jochen.briesen@fu-berlin; jochen.briesen@uni-konstanz.de)
}

\begin{abstract}
This paper aims to delineate the class of aesthetic judgments linguistically. The main idea is that aesthetic judgments can be specified by a certain set of assertibility conditions, i.e., by norms that govern appropriate speech-acts. This idea is spelled out in detail and defended against various objections. The suggestion leads to an interesting account of aesthetic judgments that is theoretically fruitful: It provides the basis for a non-circular and satisfying characterization of the whole domain of aesthetic research and it marks an important linguistic difference between aesthetic judgments and judgments of personal taste.
\end{abstract}

Keywords. Aesthetic judgment, acquaintance principle, assertibility condition

\section{Introduction}

What differentiates aesthetic judgments, aesthetic experiences, and aesthetic properties from non-aesthetic judgments, experiences, and properties? It is hard to answer one of these questions without already presupposing an answer to at least one of the others. Aesthetic judgments, for example, are often characterized as judgments that refer to aesthetic properties or as judgments triggered by aesthetic experiences. However, the aesthetic literature seems to suggest that both of these options quickly run into circularity. Philosophers on all sides of the debate concerning the structure and metaphysics of aesthetic properties implicitly or explicitly individuate these properties as the properties the predicates of aesthetic judgments refer to, thereby rendering the first option uninformativly circular. ${ }^{1}$

${ }^{1}$ Monroe Beardsley, Aesthetics: Problems in the Philosophy of Criticism (New York: Harcourt, Brace and World, 1958), 93; Alan Goldman, 'Realism about Aesthetic Properties', The Journal of Aesthetics and Art Criticism 51 (1993): 31-37; Derek Matravers, Derek, 'Aesthetic Properties I', Aristotelian Society Supplementary Volume 79 (2005): 191-210; Jerrold Levinson, 'Aesthetic Properties II', Aristotelian Society Supplementary Volume 79 (2005): 211-227; John 
The same seems to be true with respect to the second option. Faced with the fact that experiences we would like to count as genuinely aesthetic are so diverse with respect to their phenomenal and other intrinsic characteristics, many philosophers have turned to an external or content-oriented approach regarding those experiences. ${ }^{2}$ Noel Carroll, who carefully worked out probably the most convincing content account of aesthetic experiences writes: "An aesthetic experience of an object is an experience that is directed at the form of the object, its expressive and aesthetic properties, and the interaction among these elements." "Note that in specifying the content in question, Carroll refers to aesthetic properties. However, if it is correct that aesthetic properties can only be specified via recourse to aesthetic judgments, then we are faced with the circularity-problem again: What is an aesthetic judgment? It is a judgment accompanied or triggered by an aesthetic experience. What is an aesthetic experience? It is an experience of an aesthetic property of an object. What is an aesthetic property? It is a property an aesthetic judgment refers to.

Of course, these short remarks cannot prove conclusively that specifying aesthetic judgments via recourse to aesthetic properties or aesthetic experiences is doomed to fail. Maybe there is a way to solve these circularity problems or maybe the circularity involved in specifying the aesthetic domain of research is not as problematic as it appears at first. However, as long as we agree that a non-circular specification of a domain of research would be preferable, these remarks should suffice to motivate the following question: Is there a way to specify aesthetic judgments without recourse to aesthetic properties and aesthetic experiences thereby circumventing potential problems of circularity from the outset?

In this paper I want to investigate whether we can give a positive answer to this question. More precisely, I will discuss the prospects of a noncircular linguistic specification of aesthetic judgements on the basis of which other aesthetic notions could be specified. The envisaged linguistic specifications aims to classify aesthetic judgments via recourse to a certain set of assertibility conditions, i.e., via a certain set of norms that govern when an utterance is appropriate.

The specification I am looking for is supposed to meet the following conditions of adequacy: (A) non-circularity, in the abovementioned sense; (B) impartiality, in the sense that no serious theoretical option with respect to the meaning of aesthetic judgments is excluded from the outset; (C) extensional adequacy, in the sense that all paradigmatic examples of aesthetic judgments

Bender, 'Aesthetic Realism 2', in Jerrold Levinson (ed.), The Oxford Handbook of Aesthetics (Oxford: OUP, 2005), 80-98.

2 James Shelley, 'The Concept of the Aesthetic', in Edward N. Zalta (ed.), The Stanford Encyclopedia of Philosophy (Winter 2017 Edition), sec. 2.4, URL=<https:// plato.stanford. edu/archives/win2017/entries/aesthetic-concept/>; Noel Carroll, 'Aesthetic Experience Revisited', The British Journal of Aesthetics 42 (2002), 145-168; Noel Carroll, 'Aesthetic Experience: A Question of Content', in Matthew Kieran (ed.), Contemporary Debates in Aesthetics (Oxford: Blackwell, 2006), 69-97.

${ }^{3}$ Carroll, 'Aesthetic Experience', 98. 
and all paradigmatic examples of non-aesthetic judgments are classified accordingly; (D) theoretical fruitfulness, in the sense that the characterization exhibits some kind of benefit with respect to the scientific investigation of aesthetic phenomena.

Two points concerning this list should be noted. First, only extensional adequacy is required. The characterization does not aim to specify the essence or the nature of aesthetic judgments. The envisaged characterization simply aims to extensionally delineate the class of aesthetic judgments. In this sense, the suggested characterization of aesthetic judgments should only be considered a first step within a substantial theory of aesthetic judgments. ${ }^{4}$ Second, exactness in the sense that the characterization has to definitely settle controversial or in a certain sense unclear cases is not included in the conditions of adequacy. It might be that the class of aesthetic judgments does not have sharp boundaries.

The rest of the paper is organized as follows: In Section 2, I will introduce the new linguistic specification of aesthetic judgments. In Section 3, the suggested specification is clarified by considering various challenges to it. Answering these concerns will lead to important modifications and extensions. In section 4, remaining objections will be considered and dismissed. Finally, in Section 5, I will briefly summarize the discussion and explain in what sense the suggested linguistic specification of aesthetic judgments is theoretically fruitful.

\section{Aesthetic statements and the linguistic acquaintance principle}

What is an aesthetic judgment? We might answer this question by giving a paradigmatic example, such as " $X$ is beautiful." However, focusing only on judgments of beauty seems to restrict the theoretical focus. In a series of seminal papers, Frank Sibley highlighted the great variety of judgments that are important for an aesthetic theory. ${ }^{5}$ Paradigmatic examples of aesthetic judgments besides judgments of beauty include:

$X$ is graceful/ elegant/ dynamic/ majestic/ dainty/ unified/ balanced/ vibrant/ moving/ somber etc.

However, widening the perspective in this way is accompanied by the need to specify the class of aesthetic judgments on the basis of some criteria. In this

\footnotetext{
${ }^{4}$ Eventually, we want a theory concerning the nature of aesthetic judgments, their semantics and pragmatics, their variable degree of evaluation, their epistemology, etc. However, in order to develop such a substantial theory, we need to extensionally specify the object of investigation first.

${ }^{5}$ Frank Sibley, 'Aesthetic Concepts', The Philosophical Review 68 (1959), 421-50; 'Aesthetic and Nonaesthetic', The Philosophical Review 74 (1965), 135-59.
} 
paper I will suggest linguistic features on the basis of which aesthetic judgements can be differentiated from non-aesthetic ones.

However, before I can introduce the linguistic specification of aesthetic judgments, some preliminary remarks are in order. The term "judgment" is ambiguous between an explicit and sincere statement and the thought or belief that could be expressed by such a statement. For what follows it will be useful to disambiguate "aesthetic judgment" and differentiate explicitly between aesthetic statements and the mental attitudes (aesthetic thoughts or beliefs) that are expressed by such statements. Furthermore, aesthetic statements (i.e., the utterance of certain sentences in a specific context) need to be differentiated from aesthetic sentences (i.e, sentences that contain at least one aesthetic term, namely an aesthetic adjective or predicate). A linguistic specification of aesthetic judgments could either be developed as a specification of aesthetic sentences or as a specification of aesthetic statements.

In my view the chances of giving a satisfying specification of aesthetic sentences (or other aesthetic expressions) are rather dim. Louise McNally and Isidora Stojanovic recently suggested a linguistic specification of aesthetic adjectives. ${ }^{6}$ They explicitly acknowledge that given their criteria for aesthetic adjectives, many of the terms that aestheticians (either in philosophy or psychology) take to be paradigmatic examples of aesthetic terms are not classified accordingly. In order to soften that blow, McNally and Stojanovic accept that these other and by their lights non-aesthetic adjectives can nevertheless be used to make aesthetic statements. ${ }^{7}$ So even if one follows their specification of aesthetic adjectives an important question remains: What differentiates aesthetic statements (i.e., the aesthetic use of certain terms) from non-aesthetic statements?

It is also worth noting that the question what differentiates aesthetic from non-aesthetic statements becomes even more pressing, if one realizes that even a sentence with a paradigmatic aesthetic adjective such as " $X$ is beautiful", can in certain contexts be used to make a non-aesthetic statement. ${ }^{8}$ Thus, if a linguistic specification of aesthetic judgments is supposed to help clarifying the domain of investigation of an aesthetic science, it seems to be more promising to concentrate on aesthetic statements (utterances) than on aesthetic sentences or words. In what follows I will do just that, i.e., I will try to develop a non-circular linguistic specification not of aesthetic sentences or terms but of aesthetic statements.

In doing so I will suggest a certain set of assertibility conditions for those statements. The distinction between truth conditions and assertibility conditions is widely accepted and put to use in many areas of philosophy and linguistics. In contrast to truth conditions, assertibility conditions are norms

\footnotetext{
${ }^{6}$ Louise McNally and Isidora Stojanovic, 'Aesthetic Adjectives', in J.O. Young (ed.), Semantics of Aesthetic Judgments (Oxford: OUP 2017), 17-37.

${ }^{7}$ Ibid., 33-34

8 Consider, for example: "Bringing flowers to the party was a beautiful gesture." See Sibley, 'Aesthetic Concepts', 421, for a comparable observation.
} 
that govern appropriate speech-acts. Even though a sentence "p" might be true, uttering it in a certain context could still be inappropriate, in the sense that it flouts an assertibility condition.

The following acquaintance principle formulates a well-known assertibility condition for all statements that are generally considered to be paradigmatic examples of aesthetic statements:

(LAP) Linguistic Acquaintance Principle: $S$ 's aesthetic statement " $p$ " is appropriate only if $S$ has experienced for herself the object " $p$ " refers to.

(LAP) is very plausible. Take a look at these paradigmatic examples of aesthetic statements: " $X$ is beautiful/ elegant/ graceful/ vibrant/ dynamic/ majestic." Suppose in conversation with me you made such a statement and I took your word for it, thereby forming the belief that $X$ is very beautiful/elegant and so on. Even if we, in contrast to pessimists with respect to aesthetic testimony, accept that this belief of mine is justified, it would nonetheless be very strange and inappropriate if I were to say to a third party: " $X$ is beautiful/elegant/... ." Usually, when we are in such a scenario, we weaken the statement in question by prefacing the statement with, "According to a friend," or we say "X is supposed to be beautiful/elegant/... ." Thus, at least prima facie (LAP) seems very plausible. ${ }^{10}$

The plausibility of the principle can also be highlighted by the oddness of the sentences of the following kind: "It's a wonderful novel; insightful and moving, with a beautiful and bewitching language. It's such a shame that I have never read it." ${ }^{11}$ Even though this sentence does not constitute a contradiction, it is nevertheless massively infelicitous. By recourse to (LAP), the infelicity of such a statement can be easily explained: The second half of the sentence claims that the conditions for appropriately stating the first part of the sentence are not satisfied, and the statement is therefore infelicitous.

Or consider the following conversations:

(1) A: "The new James Turell installation is beautiful." $B$ : "Yeah? When did you see it?" $A$ : "Oh, I haven't yet."

(2) A: "The new Sophia Coppola movie is heart-breaking, thoughtprovoking, and elegant."

\footnotetext{
${ }^{9}$ This is even true for art historical texts and the comments therein that are concerned with artworks that do not exists anymore.

${ }^{10}$ Note that something along the lines of (LAP) is probably true for all statements that involve wh-exclamatives or intensifiers, such as: "What a big crowd that was!"; "His hair is sooo long!" What I am claiming is that aesthetic statements meet (LAP) even in the absence of these linguistic devices.

11 Keren Gorodeisky, 'A New Look at Kant's View of Aesthetic Testimony', The British Journal of Aesthetics 50 (2010), 53; Jon Robson, 'Aesthetic Testimony', Philosophy Compass 7 (2012), 4 .
} 
B: "Where did you see it? I thought they closed our theater down."

A: "Oh, I haven't seen the movie yet."

In both cases person $B$ could obviously blame $A$ for making the statements. Even though it might be epistemically appropriate for $A$ to believe that the installation or the movie is beautiful or elegant, she should not utter the corresponding sentence if she did not see the installation or the movie herself. Mary Mothersill puts the point as follows: "If someone praises a movie [...], and it then emerges that he hasn't actually seen it, we feel not just annoyed but as if we'd been lied to." ${ }^{\prime 12}$ Thus, (LAP) is plausible and widely accepted. ${ }^{13}$

The question, why (LAP) holds, is interesting and surprisingly hard to answer. ${ }^{14}$ In the context of this paper, however, the important question is: Can we use (LAP) in order to specify aesthetic statements? Consider the following suggestion:

Specification $_{(\mathrm{LAP})}: S$ 's utterance of " $p$ " is an aesthetic statement if and only if the appropriateness of $S$ 's utterance of " $p$ " is conditional on $S$ 's having experienced for herself the object " $p$ " refers to.

At first, one might think that this specification is unconvincing for the simple reason that (LAP) not only holds for aesthetic statements but for all kinds of statements that involve supposedly response-dependent terms like " $X$ is yellow," " $X$ is loud," and so on. However, this is not true. If my friend is trustworthy and she told me that her new bike is yellow, I can felicitously utter with respect to a third party: "My friend's bike is yellow." I can felicitously utter this sentence even though I have not seen the bike for myself. However, if she told me that her bike is elegant, I could not appropriately utter the corresponding sentence to a third party without having seen the bike for myself.

\footnotetext{
12 Mary Mothershill, Beauty Restored (London: Clarendon Press, 1984), 168.

13 Note that the principle also plays an important role in the growing literature on aesthetic testimony. Pessimists with respect to aesthetic testimony often use (LAP) to defend their view. They use the linguistic acquaintance principle (LAP) to argue for an epistemic acquaintance principle, which implies that aesthetic testimony is impossible. However, all sides of the debate, pessimists and optimists alike, accept the linguistic version of the principle (LAP). They only differ over the question whether (LAP) could be used to argue for a pessimist view regarding aesthetic testimony. For more examples of philosophical debates in which something along the lines of (LAP) is put to use, see Jon Robson, 'Norms of Belief and Norms of Assertion in Aesthetics', Pbilosophers' Imprint 15 (2015), 1.

${ }^{14}$ For explanations of why (LAP) holds, see: Dilip Ninan, 'Taste predicates and the acquaintance inference', Proceedings of Semantics and Linguistic Theory (SALT) 24 (2014), 290309; Alexander Dinges, 'Relativism, Disagreement and Testimony', Pacific Philosophical Quarterly (2017), 1-23; Nils Franzén, 'Aesthetic Evaluation and First-hand Experience', Australasian Journal of Philosopby 96 (2018), 669-682.
} 
Furthermore, specifying aesthetic statements via recourse to (LAP) is promising because this specification meets the abovementioned adequacy conditions (A) and (B): It is non-circular and impartial. That Specification ${ }_{(\mathrm{LAP})}$ is non-circular is easy to see-after all, in Specification (LAP) $_{\text {- }}$ aesthetic statements are not specified via recourse to any other aesthetic notion. Furthermore, Specification $_{(\mathrm{LAP})}$ is impartial, it does not rule out serious options with respect to the semantics of aesthetic statements. Neither expressivism, contextualism, objectivism, or relativism is inconsistent with the truth of Specification ${ }_{(\mathrm{LAP})}{ }^{15}$ The remaining question is whether Specification (LAP) $_{1}$ meets adequacy conditions

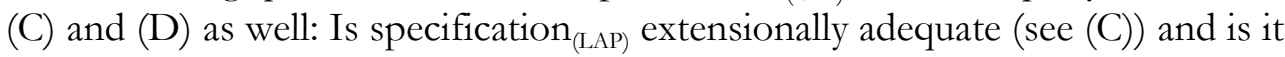
theoretically fruitful (see (D))?

\section{Clarifying and modifying the linguistic specification}

In this section I will discuss three important challenges regarding the extensional adequacy of Specification ${ }_{(\mathrm{LAP})}$. Before discussing these challenges, however, let me make it explicit that I will exclusively focus on singular aesthetic statements, such as utterances of sentences like " $X$ is $F$ " or a comparable form that refer to single objects. In (LAP) and Specification ${ }_{(\mathrm{LAP})}$ " $p$ " stands for singular sentences of this kind. For general aesthetic statements like "All Xs are F," further complications arise that cannot be discussed within this paper.

\subsection{First challenge and modification}

Specification $_{(\mathrm{LAP})}$ differentiates aesthetic statements from other statements by a norm of utterance that refers to first-hand experiences of the speaker. How should we understand the notion "experience" here? At first, it seems reasonable to understand it as perceptual experience. However, should we interpret the term as referring to direct or indirect perceptual experiences or both?

To utter appropriately the paradigmatic aesthetic sentence, " $X$ is beautiful," is it really necessary to perceptually experience $X$ directly? That seems too strong a requirement. In some cases, it seems fine to utter, " $X$ is beautiful," even though I have not seen $X$ directly but only seen a photograph of $X$. The same seems true with respect to the auditory sense and other sense modalities.

\footnotetext{
${ }^{15}$ For a short and good introduction of these positions, see John MacFarlane, Assessment Sensitivity: Relative Truth and Its Applications (Oxford: OUP, 2014), 1-21. He introduces the main theses of the positions with respect to " $X$ is tasty". However, the main theses can easily be transferred to aesthetic sentences, such as " $X$ is beautiful."
} 
Therefore, we need to construe "experience" here in such a way to allow for direct and indirect perceptual experiences alike. ${ }^{16}$

However, it is not fully clear what ways of indirectly perceiving an object should be allowed. It seems reasonable that a color photograph from the correct angle and distance should be allowed in most cases-but what about a black-and-white photo or a blurry one? It is hard to give a principled and general answer to this question. Building on insights of Robert Hopkins, one could try to give a general answer by claiming that all ways of indirectly perceiving that let us not only perceive but also enjoy the aesthetic properties of the object or that allow us to have the same aesthetic experiences we would have by directly perceiving the object should be allowed. ${ }^{17}$ This answer might be true, but it is not helpful within the context of this paper because it refers to aesthetic properties and aesthetic experiences, thereby running the risk of sliding into a circular characterization. Thus, in specifying how to understand the term "experience" in Specification ${ }_{(\mathrm{LAP})}$, we have to content ourselves with the somewhat vague and imprecise observation that the term has to cover direct and at least some ways of indirect perceptual experiences.

Unfortunately, there is another complication. It seems reasonable to allow that some aesthetic judgments refer to objects that are not experientially observable at all. Suppose I have composed a poem or established a mathemical proof but have never written it down. In a certain sense it seems perfectly fine to make an aesthetic statement about the poem or the prooffor example, that it is beautiful or elegant-even though I have not perceptually experienced the object the statement refers to. Thus, "experience" in Specification $_{(\mathrm{LAP})}$ should be understood in such a way that it allows for other forms of experience (other forms of acquaintance) besides perceptual experience. How should we spell out these other forms of experience or acquaintance in detail? Even though this in an interesting question, for the purposes of this paper it is not necessary to answer it in detail, and we can content ourselves with the somewhat imprecise requirement that "experience" in Specification $_{(\mathrm{LAP})}$ needs to cover direct and some forms of indirect perceptual experience as well as some forms of non-perceptual experiences.

Incorporating these issues results in the following suggestion:

Linguistic Specification (LAP)1 . S's utterance of " $p$ " is an aesthetic statement if and only if the following conditional holds: $S$ 's utterance of " $p$ " is appropriate only if (i) $S$ perceptually experienced the object to which " $p$ " refers in a direct or an apt indirect way, or (ii) in case " $p$ "

\footnotetext{
${ }^{16} \mathrm{I}$ am assuming here that a photograph really lets us perceive the depicted object, albeit just indirectly, cf. Kendall Walton, 'Transparent Pictures: On the Nature of Photographic Realism', Nous 18 (1984), 67-72.

17 Robert Hopkins, 'Pictures and Beauty', Proceedings of the Aristotelian Society 97 (1997), 177-194; 'How to form Aesthetic Belief: Interpreting the Acquaintance Principle', Postgraduate Journal of Aesthetics 3 (2006), 91-92.
} 
refers to an abstract object, $S$ is acquainted with that object in some relevant non-perceptual way.

Does the modified Specification ${ }_{(\mathrm{LAP}) 1}$ formulate a necessary condition for being classified as an aesthetic statement? Even with respect to the modified principle, counterexamples can be posed. Suppose you ask me how Sarah is doing and I reply: "She is having a great time! She saw a beautiful play by her favorite director yesterday." This statement seems appropriate even though I have not seen the play myself. However, in this case, it is natural to assume that the play in question was one that Sarah judged to be beautiful (perhaps by calling it "beautiful") and I am tying my statement to Sarah's judgment. In the literature on predicates of personal taste, this is called an exocentric reading of the predicate in question. ${ }^{18}$ These uses contrast with the more usual autocentric uses, in which the speaker does not ty her statement to another person's judgment. Thus, in order to sidestep these kind of counterexamples we need to restrict Specification $\mathrm{LAPP} 1_{1}$ to autocentric uses of sentences.

Other apparent counterexamples are statements concerning doubles, copies, and replicas. Assume my neighbor bought a new car that I have not seen yet. However, I know which model and color it is and I have seen other cars of this model and color. In this case, experiencing my neighbor's car for myself does not seem to be a necessary condition to felicitously utter:

(1) My neighbor's new car is beautiful.

Because (1) obviously is an aesthetic statement, Specification ${ }_{(\mathrm{LAP}) 1}$ is inadequate. It is not necessary for an aesthetic statement to conform to (LAP).

Specification $_{(\mathrm{LAP}) 1}$ can be defended against this objection in various ways. I will mention two. First, one could claim that (1) does not really make an aesthetic claim about the concrete car of my neighbor, but rather about a certain car model. A car model is a universal (a type) with many instances (many tokens), and the concrete car of my neighbor is an instance of such a model. If one further claims that to experience or be acquainted with universals (types) of a certain sort, like a car model, it is enough to perceive one of its instances perceptually, then the abovementioned case does not constitute a counterexample. Second, in response to the supposed counterexample, one could easily modify Specification $_{(\mathrm{LAP}) 1}$ by claiming that one either has to experience the object " $p$ " refers to or a (perfect) double of this object.

The first response to the supposed counterexample is restricted in a certain sense; it can only be transferred to supposed counterexamples where instances of a universal are involved. The second response, which would lead to a modification of Specification ${ }_{(\mathrm{LAP}) 1}$, is not restricted in this sense. However,

18 Peter Lasersohn, 'Context dependence, disagreement, and predicates of personal taste', Linguistics and Philosophy 28 (2005), 643-686; Ninan, 'Taste predicates and the acquaintance inference', 291-292. 
the clearest cases where we can felicitously utter an aesthetic sentence without experiencing the object ourselves involve cases where universals and instances of universals are involved. Thus, we can concentrate on the first response and stick to the simpler version of Specification ${ }_{(\mathrm{LAP}) 1}$, keeping in mind that it could be easily modified along the indicated lines of the second response if necessary.

\subsection{Second challenge and modification}

According to Specification ${ }_{(\mathrm{LAP}) 1}$, being governed by a certain utterance norm is a necessary and sufficient condition for being an aesthetic statement. In the previous subsection we considered whether the linguistic specification really formulates a necessary condition for aesthetic statements. In the following subsections we will ask whether it formulates a sufficient one. Is it sufficient for being correctly classified as an aesthetic statement to be governed by the following norm?

$S$ 's utterance of " $p$ " is appropriate only if (i) $S$ perceptually experienced the object to which " $p$ " refers in a direct or an apt indirect way, or (ii) in case " $p$ " refers to an abstract object, $S$ is acquainted with that object in some relevant non-perceptual way (see Specification $\left._{(\mathrm{LAP}) 1} \cdot\right)^{19}$

Here are some examples that seem to show that this is not the case:

(2) My arm hurts.

(3) This apple seems yellow to me.

(4) I heard the plane crash.

Utterances of sentences (2)-(4), as well as their negations, all seem to be governed by the utterance norm formulated in Specification $_{(\mathrm{LAP}) 1}$. Thus, according to Specification $\mathrm{LAPP}_{(\mathrm{P})}$, (2)-(4) would have to be considered aesthetic statements. However, utterances of (2)-(4) are pre-theoretically and traditionally not considered to be aesthetic statements. Thus, Specification (LAP)1 $_{1}$ does not formulate a sufficient condition for such statements. How can we solve this problem?

(2)-(4) not only refer to objects: my arm, an apple, and a plane but also explicitly describe my experiences of these objects. In this sense (2)-(4) are explicitly about mental or phenomenal states of potential speakers of these

\footnotetext{
19 The reader might think that it cannot formulate a sufficient condition because by adding certain words to a sentence almost every sentence will turn into one that can only be uttered appropriately, if the speaker had first-hand experience of the object in question. For example, consider wh-exclamatives, declarative exclamatives, or intensifiers, such as: "What a big crows that is!"; "Boy, this crowd is big!"; "This crowd is sooo big!" However, Specification(LAP)1 should be understood as claiming that aesthetic statements have this feature even in the absence of such devices (see fn. 10).
} 
sentences. Thus, it is not at all surprising that a speaker can appropriately utter (2)-(4) only if she has experienced for herself the objects these sentences refer to. Thus, in response to the problem raised by (2)-(4) one could modify Specification $_{(\mathrm{LAP}) 1}$ by adding a condition excluding the utterance of sentences that explicitly describe mental or phenomenal states of the speaker in experiencing an object:

Specification $_{(\mathrm{LAP}) 2}: S$ 's utterance of " $p$ " is an aesthetic statement if and only if:

(a) $S$ 's utterance of " $p$ " is appropriate only if (i) $S$ perceptually experienced the object to which " $p$ " refers in a direct or an apt indirect way, or (ii) in case " $p$ " refers to an abstract object, $S$ is acquainted with that object in some relevant non-perceptual way.

(b) In uttering " $p$," $S$ is not explicitly describing the characteristics of the experience that $S$ has while experiencing the object to which " $p$ " refers, nor is " $p$ " translatable, without loss, into such a sentence.

By adding (b), utterances of (2)-(4) are excluded from the class of aesthetic statements. These sentences either explicitly describe mental or phenomenal characteristics of the experience the speaker has while perceiving the object to which the sentences refer. Or they can be translated, without loss, into such a sentence, i.e., into a sentence that explicitly describes the experience of my arm as a painful experience (see (2)), the experience of this apple as having the specific phenomenal characteristic of seeming yellow (see (3)), or a specific auditory experience of the plane as an experience of the plane crashing.

However, does (b) exclude too much? Aren't there at least some paradigmatic aesthetic statements that are translatable, without loss, into statements explicitly describing characteristics of the experiences potential speakers have while experiencing the object to which the statement in question refers? Consider the following paradigmatic example of an aesthetic statement:

\section{(5) $X$ is beautiful.}

The following sentence (6) is a candidate of a translation of (5) into a sentence that explicitly describes the phenomenal or mental characteristics of a potential speaker (for simplicity's sake let us assume that " $X$ " in (5) refers to an object that can be perceptually experienced):

(6) In perceiving $X$, I have a pleasant sensual experience.

In order to check whether (6) can be considered an appropriate translation of (5), one has to check whether the two sentences can be substituted for one 
another in various conversational settings without significant semantic or pragmatic effects. ${ }^{20}$

It is easy to find cases that illustrate that the sentences in question cannot be substituted without significant effects of this kind:

(7) In perceiving Pollock's One: Number 31 I have a pleasant sensual experience, but I am unsure whether Pollock's One: Number 31 is beautiful.

(8) In perceiving Pollock's One: Number 31 I have a pleasant sensual experience, but I am unsure whether in perceiving Pollock's One: Number 31 I have a pleasant sensual experience.

(8) differs from (7) with respect to the second conjunct: "Pollock's One: Number 31 is beautiful" is substituted by "In perceiving Pollock's One: Number 31 I have a pleasant sensual experience." This substitution goes along with a dramatic change: (8) is an instance of a Moorean Paradox such as sentences of the form "p, but I do not believe that p," whereas (7) is not. In contrast to (8), uttering (7) is not absurd at all. Thus, in this case the sentences "Pollock's One: Number 31 is beautiful" and "In perceiving Pollock's One: Number 31 I have a pleasant sensual experience" cannot be substituted for each other without significant semantic or pragmatic effects.

Another example is concerned with the phenomenon generally (but slightly misleadingly) known as the problem of lost disagreement.

(9) A: Pollock's One: Number 31 is beautiful.

B: Pollock's One: Number 31 is not beautiful.

(10) A: In perceiving Pollock's One: Number 31 I have a pleasant sensual experience.

B: In perceiving Pollock's One: Number 31 I do not have a pleasant sensual experience.

Conversations (9) and (10) can both be described as cases of disagreement. Note, however, that the kind of disagreement in these two cases is significantly different. Only in conversation (9), the disagreement between $A$ and $B$ can be highlighted by the use of explicit disagreement markers "No" or "You are mistaken." If we add these markers to the conversations in (9) and (10) we get:

(9*) A: Pollock's One: Number 31 is beautiful.

B: No/You are mistaken, Pollock's One: Number 31 is not beautiful.

\footnotetext{
${ }^{20}$ Nothing in the following discussion depends on the specifics of the translation I have suggested. If the reader is unsatisfied with my suggestion, I invite her to replace my suggestion with her favorite candidate of such a translation. As long as the sentence explicitly describes certain characteristics of the experience of a potential speaker, the following arguments will apply.
} 
(10*) A: In perceiving Pollock's One: Number 31 I do have a pleasant sensual experience.

B: \# No/You are mistaken, in experiencing Pollock's One: Number 31 I do not have a pleasant sensual experience.

In $\left(10^{*}\right)$ the disagreement markers are obviously inappropriate because in uttering, "in experiencing Pollock's One: Number 31 I do not have a pleasant sensual experience," $B$ obviously does not negate the proposition that $A$ expressed in uttering the corresponding sentence. After all, they are speaking about different persons. ${ }^{21}$ In $\left(9^{*}\right)$, however, the markers are appropriate. Thus, the two sentences cannot be substituted for one another.

So even with respect to " $X$ is beautiful"-which is probably the most plausible candidate of a paradigmatic aesthetic statement that can be translated into a statement that describes characteristics of experiences a speaker has while experiencing the object in question-it has been shown that such a translation is not without loss. The same is true with respect to other paradigmatic aesthetic statements such as " $\mathrm{X}$ is elegant/graceful/ somber etc." Thus, by adding (b) to the specification, counterexamples (2)-(4) are excluded without thereby excluding paradigmatic examples of aesthetic statements.

However, is Specification ${ }_{(\mathrm{LAP}) 2}$ unsatisfactory in another respect? Does it exclude serious theoretical options with respect to the meaning of aesthetic statements right from the start, thereby losing the feature of meeting adequacy condition (B) (see section 1)? The major theoretical options are various forms of contextualism (speaker-subjectivism), expressivism, objectivism, and relativism.

A certain form of Contextualism, namely speaker-subjectivism, claims that aesthetic statements have the same semantic content as sentences concerning the experiential or mental state of the speaker. Thus, according to such an account (5) and (6) are semantically synonymous:

(6) $X$ is beautiful.

(6) In perceiving $X$, I have a pleasant sensual experience.

However, faced with the abovementioned data, speaker-subjectivists nonetheless accept that in many conversational settings these sentences cannot be substituted for each other. In this sense they accept that one cannot translate (5) without loss into (6). Can speaker-subjectivists, nonetheless, rationally maintain their position? Yes, they can. They could, for example, tell some pragmatic story why, despite their semantic synonymy, (5) and (6) cannot

${ }^{21}$ Note that I am not claiming that $B$ can never appropriately utter the term "No" or "You are mistaken" as a response to $A$. In $\left(10^{*}\right), B$ could, for example, appropriately say, "No, I cannot believe that," or, "You are mistaken, the painting is not by Pollock," thereby negating a presupposition of $A$ 's statement. What I am claiming is that $B$ cannot appropriately use "No" in combination with the negation of the exact same sentence that $A$ used. 
be substituted for each other in many conversational settings. Or, in order to solve the problem of lost disagreement, they could modify their position, claiming that " $X$ is beautiful" is not semantically synonymous to "In perceiving $\mathrm{X} I$ have a pleasant sensual experience" but to "In perceiving $\mathrm{X}$ we have a pleasant sensual experience," where "we" refers to the speaker and the hearer of the sentence or some other group including the speaker and hearer. Thus, specifying the class of aesthetic statements via recourse to (a) and (b), does not exclude speaker-subjectivism as a theoretical option with respect to the meaning of aesthetic statements right from the start.

The same is true with respect to all the other major theoretical options, namely expressivism, objectivism, and relativism. Proponents of all these accounts accept that an aesthetic statement does not explicitly describe the experience of a potential speaker nor can it be translated without loss into such a sentence. In contrast to speaker-subjectivists, however, they can account for this via purely semantic reasons. After all, proponents of all these positions deny that sentences such as " $X$ is beautiful/elegant etc." and sentences about experiences of potential speakers are semantically synonymous. If these sentences are not synonymous, then it is not surprising that they cannot be substituted for each other in various conversational settings.

In summary, by incorporating (b), Specification (LAP)2 $_{\text {can handle the }}$ counterexamples (2)-(4) without excluding paradigmatic instances of aesthetic statements or serious theoretical options with respect to their meaning.

\subsection{Third challenge and modification}

Even though Specification (LAP)2 $_{2}$ is the most promising suggestion so far, it is still confronted with counterexamples:

(12) $X$ is tasty/delicious.

(13) $X$ is enjoyable/fun.

At least some uses of (12)-(13) seem to meet conditions (a) and (b) of Specification $_{(\mathrm{LAP}) 2}$ :

(a) $S$ 's utterance of " $p$ " is appropriate only if (i) $S$ perceptually experienced the object to which " $p$ " refers in a direct or an apt indirect way, or (ii) in case " $p$ " refers to an abstract object, $S$ is acquainted with that object in some relevant non-perceptual way.

(b) In uttering " $p$, , $S$ is not explicitly describing the characteristics of the experience that $S$ has while experiencing the object to which " $p$ " refers, nor is " $p$ " translatable, without loss, into such a sentence.

However, is it really plausible to consider utterances of (12)-(13) as aesthetic statements? An adequate classification of aesthetic statements should cover all statements that aestheticians (working in philosophy or psychology) consider 
to be paradigmatic examples of such statements, and it should exclude all statements that aestheticians typically exclude.

Many aestheticians think that the delight we receive by olfactory, tactile, and gustatory experiences are merely sensuous and not genuinely aesthetic. Based on this assumption, many aestheticians do not take judgments like "Orange juice is delicious" or "Massages are enjoyable" to be aesthetic judgments. Even philosophers that oppose this standard view and claim that tastes, smells, and tactile experiences can be of aesthetic value are usually reluctant to classify utterances of (12)-(13) as aesthetic statements. ${ }^{22}$ This is why in the relevant literature (12)-(13) are often referred to as judgments of (personal) taste.

Nonetheless, by the lights of Specification ${ }_{(\mathrm{LAP}) 2}$ utterances of (12)-(13) are classified as aesthetic statements, because they arguably meet conditions (a) and (b). That they meet condition (a) can be easily illustrated by the oddness of the following sentences: "Orange juice is tasty, but I have never tasted it"; "Massages are enjoyable, but I have never been given one." And they seem to meet condition (b) as well, because (12)-(13) can hardly be translated without loss into sentences, which explicitly describe the experiences that potential speakers have while perceiving the objects in question. This can be illustrated by the fact that, in contrast to statements explicitly describing experiences of potential speakers, people can mark their disagreement with respect to the question whether or not something is tasty, enjoyable, or fun by using explicit disagreement markers. ${ }^{23}$

(14) A: Licorice is tasty/ roller coasters are fun/massages are enjoyable.

$B:$ No/you are mistaken, licorice is not tasty/roller coasters are not fun/ massages are not enjoyable.

In what follows, I will accept that using these markers in (14) is appropriate and that this is enough to prove that (12)-(13) do meet condition (b).

Thus, if we want to characterize aesthetic statements in a way such that (12)-(13) are not included, we have to modify the suggested criterion again. Is there a way to linguistically differentiate utterances of (12)-(13) from paradigmatic aesthetic statements, i.e. is there an interesting linguistic difference between statements of personal taste and aesthetic statements?

A possible difference might be found by comparing sufficient conditions for appropriately uttering these sentences. Condition (a) in Specification (LAP)2 $_{2}$ only formulates a necessary condition for an appropriate utterance of the

\footnotetext{
${ }^{22}$ Such views can be found in: Harold Osbourne, 'Odours and Appreciation', The British Journal of Aesthetics 17 (1977), 37-48; J.O. Urmson, 'What makes a Situation Aesthetic', Proceedings of the Aristotelian Society 31 (1957), 75-106.

${ }^{23}$ Cf. Lasersohn, 'Context dependence, disagreement, and predicates of personal taste'; Hazel Pearson, 'A Judge-Free Semantics for Predicates of Personal Taste.' Journal of Semantics 30 (2013), 643-686.
} 
sentences in question. (12) and (13) meet this necessary condition as well as paradigmatic aesthetic statements. But maybe we can differentiate (12) and (13) from aesthetic statements by formulating a sufficient utterance-condition.

The following sufficient utterance-condition seems to be plausible with respect to (12) and (13):

(SU) If you have experienced the object to which " $p$ " refers and the experience was perceptually pleasing (displeasing) to you, then uttering " $p$ " is appropriate. ${ }^{24}$

If we presuppose that no unusual circumstances prevail (i.e., the speaker has not taken any substances that alter her perceptual capacities, she does not have a cold, she does not relate very good or very bad memories with the object to which " $\mathrm{p}$ " refers, etc.), principle (SU) is plausible. This can again be illustrated by considering the oddness of certain sentences.

Take a look at the following examples (again presupposing the absence of unusual circumstances of the kind mentioned above): "I love the taste of orange juice, but I am unsure whether it is tasty"; "I love the feeling of getting a massage, but I am not sure whether it is enjoyable". These sentences are odd because there is a tension between the expressed conviction regarding the received pleasure and the unwillingness to make the corresponding tasty/enjoyable-judgment. This kind of tension is to be expected if (SU) is correct. After all, (SU) claims that in case you have experienced a massage and you enjoyed the experience, uttering "Massages are enjoyable" is appropriate.

However, with respect to paradigmatic cases of aesthetic statements, (SU) does not seem to formulate a correct utterance condition. Thus, via recourse to (SU) aesthetic statements and statements such as (12) and (13) can be differentiated. Consider statements of beauty and elegance. In order to appropriately utter " $X$ is beautiful" or " $X$ is elegant", it does not seem sufficient that you have experienced $X$ and that this experience was pleasing to you. This can be illustrated by the fact, that in contrast to the analogous tasty/enjoyable-statements the following sentences are not odd at all: "I love how this flower looks, but I am unsure whether it is elegant", "I love how Pollock's One: Number 31 looks, but I am unsure whether it is beautiful". These sentences illustrate that even though the speaker is aware of the fact that she definitely had a pleasurable visual experience of a specific flower or a painting, the speaker can still be unwilling to make a statement regarding its elegance or beauty. Thus, (SU) does not seem to formulate a sufficient condition for appropriately uttering " $\mathrm{X}$ is beautiful" or " $\mathrm{X}$ is elegant".

Furthermore, it is not hard to explain why " $X$ is beautiful" and " $X$ is elegant" do not meet (SU): These statements do not only have an evaluative but also a strong descriptive component. So in order for something to be, for example, elegant, it has to have certain descriptive features. Thus, in order to appropriately utter " $X$ is elegant" it cannot be enough to have had a

${ }^{24}$ Cf. Macfarlane, Assessment Sensitivity, 4 
pleasurable experience of $X$, at least one also has to believe that $X$ actually has some of the relevant descriptive features. Something along those lines seems to be true with respect to the more strongly evaluative aesthetic statement " $X$ is beautiful" and all other paradigmatic examples of aesthetic statements.

Thus, we can handle the supposed counterexamples (12) and (13) by adding a further condition (c) to Specification ${ }_{(\mathrm{LAP}) 2}$, which basically claims that $\mathrm{SU})$ is not a sufficient condition for appropriately uttering the statements in question. This leads to the following suggestion:

Specification $_{(\mathrm{LAP}) 3}: S$ 's utterance of " $p$ " is an aesthetic statement if and only if:

(a) $S$ 's utterance of " $p$ " is appropriate only if (i) $S$ perceptually experienced the object to which " $p$ " refers in a direct or an apt indirect way, or (ii) in case " $p$ " refers to an abstract object, $S$ is acquainted with that object in some relevant non-perceptual way.

(b) In uttering " $p$ ", $S$ is not explicitly describing the characteristics of the experience that $S$ has while experiencing the object to which " $p$ " refers, nor is " $p$ " translatable, without loss, into such a sentence.

(c) Experiencing the object to which " $p$ " refers and judging the experience as pleasurable/displeasurable (i.e., valuing it to a certain degree) is not sufficient to appropriately utter " $p$."

Admittedly, in its detailed form this specification is rather complicated, the basic idea behind it, however, is simple and plausible: Even though aesthetic statements are not explicitly about experiences of the speaker (see (b)), they can nonetheless only be uttered appropriately if the speaker herself has firsthand experience of the object the statement refers to (see (a)). However, having such first-hand experiences and enjoying or valuing these experiences in the specified ways is not sufficient to appropriately utter an aesthetic statement $(\operatorname{see}(\mathrm{c}))$.

\section{Remaining worries: good wine and great goals}

Before highlighting in which sense I take Specification (LAP) $3_{3}$ to be theoretically fruitful, I will consider and dismiss two more potential problems. Take a look at the following statements:

(15) X scored a great goal yesterday.

(16) W is a good wine.

Arguably, both of these statements satisfy the conditions (a)-(c). But should we really classify them as aesthetic statements? 


\subsection{First worry: great goals}

I agree that in certain contexts an utterance of (15) does satisfy the conditions (a)-(c). Is this a problem for the suggested account of aesthetic statements? I don't think so. In order to see why, note first that the following statements obviously satisfy the suggested conditions (a)-(c):

(17) X scored a beautiful/elegant goal yesterday.

This is the desired result. After all, we can evaluate all kinds of things aesthetically: natural objects, artifacts, artworks, abstract objects, actions, etc. So we should also be able to make aesthetic statements concerning certain performances in sports.

The difference between (15) and (18), however, is that (15) does not contain a paradigmatic aesthetic term (such as "beautiful" or "elegant") but a purely evaluative term ("great"). It is important to note, that the term "great" is highly context-sensitive. Things can be great in all kinds of respects and for all kinds of reasons.

I suggest that whenever the purely evaluative statement (15) satisfies the conditions for aesthetic statements (a)-(c), the evaluation of the sportive performance has an aesthetic dimension to it: We judge the performance as being great, in the sense that it was executed elegantly and/or beautifully and/or dynamically, etc. This is why in certain contexts an utterance of (15) satisfies (a)-(c) and is therefore rightfully classified as an aesthetic statement.

Whenever the evaluation of a sportive performance has no such aesthetic dimension to it - for example, when we judge the scoring of a goal as being great, in the sense that it was the decisive goal and it was scored in the last 10 seconds of the match — an utterance of (16) does not satisfy (a), and is therefore not classified as an aesthetic statement by the lights of the suggested Specification $_{(\mathrm{LAP} 3)}$. That in this case condition (a) is not satisfied (namely, the condition that the statement can only be uttered appropriately if the speaker herself has first-hand experience of the object the statement refers to) can be illustrated by the fact that the following statement is not infelicitous at all: " $\mathrm{X}$ scored a decisive goal in the last 10 seconds of the match, but I haven't seen it."

\subsection{Second worry: good wine}

Does the following statement satisfy the conditions (a)-(c) and should we classify it as an aesthetic statement?

(16) W is a good wine.

Again, note that the term "good" is highly context-sensitive. Things can be good in all kinds of respects. This is even true for "__ is a good wine": a wine can be good as an investment, as a gift to your grandmother, etc. Assume that context determines that by uttering (16) (and all the following examples) the speaker claims that $W$ is good as a wine. 
Does (16) - when uttered in such a context - satisfy the conditions (a)-(c) of aesthetic statements? As far as I can see, all the reasons given above as to why paradigmatic aesthetic judgments satisfy (b) and (c) can be easily transferred to (16). So by the lights of Specification ${ }_{(\mathrm{LAP}) 3}$, whether or not (16) is classified as an aesthetic statement depends on whether (16) satisfies condition (a) as well:

(a) $S$ 's utterance of " $p$ " is appropriate only if (i) $S$ perceptually experienced the object to which " $p$ " refers in a direct or an apt indirect way, or (ii) in case " $p$ " refers to an abstract object, $S$ is acquainted with that object in some relevant non-perceptual way.

Consider an utterance of the following sentence by a salesman in a wine store: "W is a good wine, but I have never tasted it." Is this utterance felicitous or not? I am not sure. (The sentence was actually uttered by the salesman in my local wine store a few days ago.) We might understand "W is a good wine" as highlighting that the wine meets certain standards for good winemaking (i.e., standards concerning the products and the various processes involved). Whether or not a certain wine meets these standards can be known without having had first-hand experience of the wine's taste, so "W is a good wine, but I have never tasted it" at least has some reading according to which it is not infelicitous. And if we accept that uttering such a sentence is not infelicitous, then (16) does not meet condition (a) and is therefore not classified as an aesthetic statement by the lights of Specification $\mathrm{LAPP}_{3}$.

However, one might rightly claim that whenever we judge that a certain wine is good as a wine, we are not only evaluating the winemaking process but also its taste, and this is why "W is a good wine, but I have never tasted it" will always sound at least somewhat odd. As far as I can see, it is simply unclear whether (16) meets (a), and thereby, it is unclear whether Specification (LAP)3 $_{3}$ classifies (16) as an aesthetic statement or not.

In my view, however, this does not amount to a serious problem for Specification $_{(\mathrm{LAP}) 3}$. It was never an aim of the specification-project to begin with that we arrive at a level of precision that excludes borderline cases. Furthermore, there is an explanation available as to why it is plausible to classify (16) as such a borderline case.

In order to formulate this explanation in detail, we have to consider evaluative judgments with respect to artworks first:

(18) The new painting in our museum is a good artwork.

Again, assume that context determines that in uttering (18) the speaker judges the painting to be good as an artwork. In such a context, the utterance of (18) is constrained by (a)-(c) and is therefore classified as an aesthetic statement. This is the desired result. After all, aestheticians typically consider statements 
concerning the value of artworks (as artworks) as paradigm examples of aesthetic statements. ${ }^{25}$

Let us return to the potentially problematic example:

(16) W is a good wine.

Based on the insight that purely evaluative statements with respect to artworks such as (18) are clear cases of aesthetic statements, we can explain why (16) constitutes a borderline case. Admittedly, classifying gourmet meals or highend wines as works of art is a bit of a stretch. However, it is widely agreed that these things are at least in some respects treated in comparable ways: In experiencing works of art, high-end wine, and gourmet meals, we embed the sensuous experience into a larger cultural context, we aim at distinguishing subtle differences in the sensuous experience on various levels, we try to identify the different styles of the creators of the objects, etc. If it is correct that we treat gourmet meals and high-end wines in a relevantly comparable way to the way we treat works of art, and if it is also true that value statements with respect to works of art are paradigm cases of aesthetic statements, then it should not be surprising that value statements with respect to gourmet meals and high-end wines turn out to be borderline cases of aesthetic statements.

\section{Consequences and benefits of the linguistic specification}

In the previous sections I have motivated, clarified, and defended an interesting specification of aesthetic statements, namely Specification $\mathrm{L}_{(\mathrm{LAP}) 3}$. The upshot of the discussion is that Specification ${ }_{(\mathrm{LAP}) 3}$ has a good chance to specify aesthetic statements satisfactorily: it is non-circular and impartial (see adequacy conditions (A) and (B)) and it is extensionally adequate (see adequacy condition $(\mathrm{C})$ ). The remaining question is: Is Specification ${ }_{(\mathrm{LAP}) 3}$ theoretical fruitful as well (see adequacy condition (D))? There are several reasons to think that it is.

First, the suggestion highlights research desiderata for a satisfactory theory concerning the meaning of aesthetic statements, namely a detailed specification of their semantics, pragmatics, and speech-act theoretic classification. Such an account should explain why conditions (a)-(c) hold. Formulating a theory that explains all conditions equally well is an interesting and challenging task.

Second, words such as "beautiful" are primarily used to make aesthetic statements. However, we can also use those words to make non-aesthetic

25 Of course most aestheticians differentiate between aesthetic and artistic values. I am not claiming that this differentiation is unwarranted or useless. I am only claiming that most aestheticians would agree that it is correct to classify statements that confer artistic value to an artwork as an aesthetic statement. 
statements. ${ }^{26}$ Furthermore, words such as "dynamic", "fragile", "lifeless", etc., are probably just as often used to make non-aesthetic statements as they are used to make aesthetic ones. Even though this is widely acknowledged, the linguistic difference between aesthetic and non-aesthetic uses of words has never been specified. Specification ${ }_{(\mathrm{LAP}) 3}$ satisfactorily fills this gap. Words are used to make an aesthetic statement if the statement is governed by the assertibility conditions (a)-(c).

Third, condition (c) of Specification ${ }_{(\mathrm{LAP}) 3}$ highlights an interesting difference between aesthetic statements and statements of personal taste. Thereby, also highlighting in which respect the widely discussed semantics and pragmatics of the latter cannot be transferred to the former.

Fourth, in Specification (LAP)3 $_{3}$ aesthetic statements are characterized without the use of other aesthetic notions. Thus, this specification might be of use in specifying those other notions: What is an aesthetic belief? Aesthetic beliefs are attitudes that are primarily expressed by aesthetic statements. ${ }^{27}$ What is an aesthetic judgment? An aesthetic judgment is either an aesthetic statement or an aesthetic belief. What is an aesthetic experience? Aesthetic experiences are experiences that cause genuine and sincere aesthetic statements or aesthetic beliefs. What is an aesthetic property? Aesthetic properties are the properties that the predicates of simple aesthetic statements refer to.

Thus, Specification ${ }_{(\mathrm{LAP}) 3}$ does not only meet the conditions of adequacy (A) $-(\mathrm{C})$, but condition (D) as well-it is theoretically fruitful in various ways.

\section{References}

Beardsley, Monroe C. 1958. Aesthetics: Problems in the Philosophy of Criticism. New York: Harcourt, Brace \& World.

Beardsley, Monroe C. 1982. The Aesthetic Point of View: Selected Essays, edidet by M.K. Wreen and D. M. Callen. London, Ithaca: Cornell University Pres.

Bell, Clive 1914/2015. Art. New York: Forgotten Books.

Bender, John W. 2005. 'Aesthetic Realism 2.' In The Oxford Handbook of Aesthetics, edited by Jerrold Levinson, 80-98. New York: Oxford University Press.

Carroll, Noel 2015. 'Defending the Content Approach to Aesthetic Experience.' Metaphilosophy 46 (2): 171-188.

\footnotetext{
26 See fn. 8.

27 Whether or not these attitudes are ordinary descriptive beliefs, or rather attitudes with a different direction-of-fit, depends on the best account with respect to the meaning of aesthetic statements.
} 
Carroll, Noel 2012. 'Recent Approaches to Aesthetic Experience.' The Journal of Aesthetics and Art Criticism 70 (2): 165-177.

Carroll, Noel 2002. 'Aesthetic Experience Revisited.' The British Journal of Aesthetics 42 (2): 145-168.

Carroll, Noel 2006. 'Aesthetic Experience: A Question of Content.' In Contemporary Debates in Aesthetics and the Philosophy of Art, edited by M. Kieran, 69-97. Oxford: Blackwell Publishers.

Cohen, Ted 1973. 'Aesthetic/Non-Aesthetic and the Concept of Taste: A Critique of Sibley's Position.’ Theoria 39 (1-3): 113-152.

Cohen, Ted 2001. 'Sibley and the Wonder of Aesthetic Language.' In Aesthetic Concepts, edited by E. Brady and J. Levinson, 23-34. New York: Oxford University Press.

DeClercq, Rafael 2002. 'The Concept of an Aesthetic Property.' Journal of Aesthetics and Art Criticism 60 (2): 167-176.

Eaton, Marcia Muelder 1994. 'The Intrinsic, Non-Supervenient Nature of Aesthetic Properties.' The Journal of Aesthetics and Art Criticism 52 (4): 383-397.

Fechner, Gustav Theodor 1871. Zur experimentellen Ästhetik. Leipzig: S. Hirzel.

Fechner, Gustav Theodor 1876. Vorschule Der Äthetik. Leipzig: Breitkopf \& Härtel.

Goldman, Alan H. 1993. 'Realism about Aesthetic Properties.' The Journal of Aesthetics and Art Criticism 51 (1): 31-37.

Gorodeisky, K. 2010. 'A New Look at Kant's View of Aesthetic Testimony.' The British Journal of Aesthetics 50 (1): 53-70.

Grice, Herbert P. 1989. Studies in the Way of Words. Cambridge, Mass.: Harvard Univ. Press.

Hegel, Georg Wilhelm Friedrich 1835/2015. Vorlesungen über die Philosophie der Kunst I. In Gesammelte Werke Bd. 28/1 (Akademie Ausgabe), edited by Niklas Hebing. Hamburg: Meiner.

Hopkins, Robert 1997. 'Pictures and Beauty.' Proceedings of the Aristotelian Society 97:177-94.

Hopkins, Robert 2006. 'How to Form Aesthetic Belief: Interpreting the Acquaintance Principle.' Postgraduate Journal of Aesthetics 3 (3): 85-99. 
Iseminger, Gary 2003. 'Aestehtic Experience.' In The Oxford Handbook of Aesthetics, edited by J Levinson, 99-1116. Oxford Handbooks Series. New York: OUP Oxford.

Iseminger, Gary 2006. 'The Aesthetic State of Mind.' In Contemporary Debates in Aesthetics and the Philosophy of Art, edited by M Kieran, 98-112. Oxford: Blackwell Publishers.

Kant, Immanuel 1790. Kritik, der Urteilskraft. In Kant's gesammelte Schriften, Akademie Ausgabe, Bd. V, Königlich Preußische Akademie der Wissenschaften zu Berlin (now de Gruyter) Berlin 1900- .

Kivy, Peter 1979. 'Aesthetic Concepts: Some Fresh Considerations.' The Journal of Aesthetics and Art Criticism 37 (4): 423-432.

Lackey, Jennifer 2011: 'Assertion and Isolated Second-hand Knowledge.' In Assertion: New Philosophical Essays, edited by J. Brown and H. Cappelen, 251276. New York: OUP.

Lasersohn, Peter 2005. 'Context dependence, disagreement, and predicates of personal taste.' Linguistics and Philosophy, 28: 643-686.

Levinson, Jerrold 2005. 'Aesthetic Properties II.' Aristotelian Society Supplementary Volume 79 (1): 211-227.

Levinson, Jerrold 2006. Contemplating Art: Essays in Aesthetics. New York: Oxford University Press.

MacFarlane, John 2014. Assessment Sensitivity: Relative Truth and Its Applications. New York: Oxford University Press.

Matravers, Derek 2005. 'Aesthetic Properties I.' Aristotelian Society Supplementary Volume 79 (1): 191-210.

Meskin, Aaron 2007. 'Solving the Puzzle of Aesthetic Testimony.' In Knowing Art: Essays in Aesthetics and Epistemology, edited by M. Kieran and D. Lopes, 109-24. Dordrecht: Springer.

Mothersill, Mary 1984. Beauty Restored. London: Clarendon Press.

Ninan, Dilip 2014. 'Taste predicates and the acquaintance inference.' Proceedings of Semantics and Linguistic Theory (SALT) 24: 290-309.

Osborne, Harold 1977. 'Odours and Appreciation.' The British Journal of Aesthetics 17 (1): 37-48. 
Palmer, Stephen E., Karen B. Schloss, and Jonathan Sammartino 2013. 'Visual Aesthetics and Human Preference.' Annual Review of Psychology 64 (1): 77-107.

Pearson, Hazel 2013. 'A Judge-Free Semantics for Predicates of Personal Taste.' Journal of Semantics 30 (1): $103-154$.

Robson, Jon 2012. 'Aesthetic Testimony.' Philosophy Compass 7 (1): 1-10.

Robson, Jon 2015: . 'Norms of Belief and Norms of Assertion in Aesthetics.' Philosophers' Imprint (15), 6:

Schellekens, Elisabeth, and Peter Goldie, eds. 2011. The Aesthetic Mind: Philosophy and Psychology. New York: Oxford University Press.

Schroeder, Mark Andrew 2010. Noncognitivism in Ethics. New York, London: Routledge.

Scruton, Roger. 1979. The Aesthetics of Architecture. London: London.

Scruton, Roger 1974. Art and Imagination: A Study in the Philosophy of Mind. South Bend, Indiana: St. Augustine's Press.

Shimamura, Arthur P, and Stephen E Palmer, eds. 2012. Aesthetic Science: Connecting Minds, Brains, and Experience. New York: Oxford University Press.

Sibley, Frank 2001. 'Tastes, Smells, and Aesthetics.' In Approach to Aesthetics, edited by Ohn Benson, Betty Redfern, and Jeremy Roxbee Cox, 207-55. New York: Oxford University Press.

Sibley, Frank 1965. 'Aesthetic and Nonaesthetic.' The Philosophical Review 74 (2): 135-59.

Sibley, Frank 1959. 'Aesthetic Concepts.' The Philosophical Review 68 (4): 421-50.

Urmson, J. O. 1957. 'Symposium: What Makes a Situation Aesthetic?'

Proceedings of the Aristotelian Society, Supplementary Volumes 31: 75-106.

Walton, Kendall L. 1984. 'Transparent Pictures: On the Nature of Photographic Realism.' Nous 18 (1): 67-72.

Weiner, Matthew 2007. 'Norms of Assertion.' Philosophy Compass 2 (2): 187-195.

Williamson, Timothy 1996. 'Knowing and Asserting.' Philosophical Review 105 (4): $489-523$.

Wollheim, Richard 1980. 'Art and Its Objects.' Cambridge: Cambridge University Press. 
Zangwill, Nick 1998. 'Two Dogmas of Kantian Aesthetics.' In Proceedings of the 11th International Congress in Aesthetics, edited by Richard Woodfield, 233-38.

Nottingham: Nottingham Polytechnic Press.

Zangwill, Nick 2014. 'Aesthetic Judgment.' The Stanford Encyclopedia of Philosophy (Fall 2014 Edition), Edward N. Zalta (ed.), URL =

< https://plato.stanford.edu/archives/fall2014/entries/aesthetic-judgment/>. 